\title{
Nicotine modulates GABAergic transmission to dopaminergic neu- rons in substantia nigra pars compacta
}

\author{
Cheng XIAO ${ }^{1, *}$, Ke-chun YANG ${ }^{2,3, *}$, Chun-yi ZHOU ${ }^{1}$, Guo-zhang JIN ${ }^{3}$, Jie WU ${ }^{2}$, Jiang-hong $\mathrm{YE}^{1, *}$ \\ ${ }^{1}$ Department of Anesthesiology, Pharmacology and Physiology, New Jersey Medical School, UMDNJ, Newark, NJ 07103, USA; ${ }^{2}$ Divisions of Neurology, \\ Barrow Neurological Institute, St Joseph's Hospital and Medical Center, Phoenix, AZ 85013, USA; ${ }^{3}$ Department of Pharmacology, Shanghai Institute of \\ Materia Medica, Chinese Academy of Sciences, Shanghai 201203, China
}

\begin{abstract}
Aim: Dopaminergic neurons in the substantia nigra pars compacta (SNc) play important roles in motor control and drug addiction. As the major afferent, GABAergic innervation controls the activity of SNc dopaminergic neurons. Although it is clear that nicotine modulates SNc dopaminergic neurons by activating subtypes of somatodendritic nicotinic acetylcholine receptors (nAChRs), the detailed mechanisms of this activation remain to be addressed.

Methods: In the current study, we recorded GABA $\mathrm{A}$ receptor-mediated spontaneous inhibitory postsynaptic currents (sIP$\mathrm{SCs}$ ) from dissociated SNc dopaminergic neurons that were obtained using an enzyme-free procedure. These neurons preserved some functional terminals after isolation, including those that release GABA.

Results: We found that both extra- and intra-cellular calcium modulates SIPSCs in these neurons. Furthermore, both nicotine and endogenous acetylcholine enhance the frequency of sIPSCs. Moreover, endogenous acetylcholine tonically facilitates sIPSC frequency, primarily by activating the a $4 \beta 2^{*}$ nAChRs on the GABAergic terminals.

Conclusion: Nicotine facilitates GABA release onto SNc dopaminergic neurons mainly via the activation of presynaptic a $4 \beta 2^{*}$ nAChRs.
\end{abstract}

Keywords: acetylcholine; dopamine; nicotine; neurons

Acta Pharmacologica Sinica (2009) 30: 851-858; doi: 10.1038/aps.2009.65

\section{Introduction}

Nicotine is the most commonly abused drug ${ }^{[1]}$. It stimulates dopaminergic (DA) neurons in the ventral tegmental area (VTA) and substantia nigra pars compacta $(\mathrm{SNc})$ by activating nicotinic acetylcholine receptors (nAChRs) ${ }^{[2-4]}$ and enhances locomotor activity ${ }^{[5,6]}$, thus conferring its rewarding effect. Multiple subtypes of nAChRs are highly expressed in midbrain neurons, including DA neurons and GABAergic neurons ${ }^{[4,7-10]}$. GABAergic neurons in the VTA and substantia nigra pars reticulata $(\mathrm{SNr})$ inhibit, respectively, DA neurons in the VTA and the $\mathrm{SNc}^{[11-13]}$. Therefore, the tuning effect of nicotine on the DA neuron can be reasonably investigated by studying both the pre- and postsynaptic components in these neural circuits.

It is well documented that the activation of presynaptic

\footnotetext{
\# These authors played an equal role in this paper.

* Correspondence to Jiang-hong YE.

E-mail ye@umdnj.edu

Received 2009-02-28 Accepted 2009-04-14
}

nAChRs facilitates the release of neurotransmitters, including GABA, glutamate, serotonin, and dopamine $e^{[3,14-16]}$. In the VTA, nicotine stimulates glutamate release by activating $\alpha 7 \mathrm{nAChRs}$ and GABA release by activating $\alpha 4 \beta 2^{*} \mathrm{nAChRs}$ (the asterisk indicates that there may be other subunits) ${ }^{[3]}$. Whereas the former effect appears to be persistent, the latter is transient, because the concentrations of nicotine achieved during smoking tend to rapidly desensitize $\alpha 4 \beta 2^{*}$ $n A C h R s^{[3,4]}$. The net effect of activation of presynaptic nAChRs would therefore preferentially be excitation of VTA DA neurons.

In the substantia nigra, $\alpha 4 \beta 22^{*} \mathrm{nAChRs}$ in SNr GABAergic neurons also play a pivotal role in modulating the activity of SNc DA neurons. Activation of SNr GABAergic neurons inhibits SNc DA neurons ${ }^{[12]}$. Chronic nicotine upregulates $\alpha 4 \beta 2 *$ nAChRs localized in SNr GABAergic neurons without changing $\alpha 4 \beta 2^{*} \mathrm{nAChR}$ levels in SNc DA neurons ${ }^{[10]}$. Due to the tonic cholinergic innervation in the substantia nigra, the specific upregulation of $\alpha 4 \beta 2^{*} \mathrm{nAChR}$ by chronic nicotine induces hyperactivity of $\mathrm{SNr}$ GABAergic neurons and 
hypoactivity of SNc DA neurons and attenuates excitation of SNc DA neurons by nicotine. SNc DA neurons receive GABAergic innervation from the dorsal striatum, globus pallidus, and $\mathrm{SNr}^{[12,17-19]}$. The expression pattern of $\mathrm{nAChRs}$ in the $\mathrm{SNr}$ is different from that in the dorsal striatum and globus pallidus ${ }^{[2,10,20,21]}$.

In this study, we determined which subtypes of nAChRs are responsible for nicotine modulation of GABA release onto SNc DA neurons. Mechanically dissociated SNc DA neurons were used to accomplish this goal, for several reasons. First, enzyme-free dissociation keeps the presynaptic receptors intact; second, the majority of neuronal processes are severed by the dissociation, facilitating space clamping; third, the resulting preparation contains only a postsynaptic neuron and presynaptic boutons, facilitating straightforward interpretation of the results; finally, this preparation allows for fast perfusion of chemicals, which can ensure accurate drug concentrations around the recorded cell and minimize the confounding effects of desensitization ${ }^{[22-28]}$.

\section{Materials and methods}

Slice preparation The care and use of animals and the experimental protocols used in this study were approved by the Institutional Animal Care and Use Committee of the University of Medicine and Dentistry of New Jersey. Midbrain slices were prepared as described previously ${ }^{[27,29]}$. In brief, rats aged 6 to 17 postnatal days were decapitated and the brains were quickly excised and coronally sliced ( 300 $\mu \mathrm{m})$ using a VF-200 Slicer (Precisionary Instruments, Greenville, NC). This was done while the brains were immersed in ice-cold artificial cerebrospinal fluid saturated with 95\% $\mathrm{O}_{2}-5 \% \mathrm{CO}_{2}$ (carbogen) containing $126 \mathrm{mmol} / \mathrm{L} \mathrm{NaCl}, 1.6$ $\mathrm{mmol} / \mathrm{L} \mathrm{KCl}, 1.25 \mathrm{mmol} / \mathrm{L} \mathrm{NaH}_{2} \mathrm{PO}_{4}, 1.5 \mathrm{mmol} / \mathrm{L} \mathrm{MgCl}_{2}$, $2 \mathrm{mmol} / \mathrm{L} \mathrm{CaCl}_{2}, 25 \mathrm{mmol} / \mathrm{L} \mathrm{NaHCO}_{3}$, and $10 \mathrm{mmol} / \mathrm{L}$ glucose. Midbrain slices were kept in carbogen-saturated artificial cerebrospinal fluid at room temperature $\left(22-24^{\circ} \mathrm{C}\right)$ for at least $1 \mathrm{~h}$ before use.

Preparation of mechanically dissociated SNc neurons Neurons with functional terminals were obtained by mechanical dissociation as described previously ${ }^{[22,27,28]}$. In brief, one midbrain slice was transferred to a $35-\mathrm{mm}$ culture dish (Falcon, Rutherford, NJ) filled with a standard external solution containing $140 \mathrm{mmol} / \mathrm{L} \mathrm{NaCl}, 5 \mathrm{mmol} / \mathrm{L} \mathrm{KCl}$, $2 \mathrm{mmol} / \mathrm{L} \mathrm{CaCl}_{2}, 1 \mathrm{mmol} / \mathrm{L} \mathrm{MgCl}_{2}, 10 \mathrm{mmol} / \mathrm{L}$ HEPES, and $10 \mathrm{mmol} / \mathrm{L}$ glucose $(320 \mathrm{mOsm}, \mathrm{pH}$ adjusted to 7.3 with Tris base). The region of SNc was identified with an inverted microscope (Nikon, Tokyo, Japan). A heavily firepolished glass pipette with a $50-\mu \mathrm{m}$ diameter tip was fixed on a homemade device. Using a manipulator, the pipette was then positioned so as to slightly touch the surface of the $\mathrm{SNc}$ region. Neurons close to the surface of the tissue were dissociated by horizontal vibration at a frequency of 15 to $20 \mathrm{~Hz}$ with a range from 0.1 to $0.3 \mathrm{~mm}$ for 2 to $5 \mathrm{~min}$. The slice was then removed. Within $20 \mathrm{~min}$, the isolated neurons adhered to the bottom of the dish and were ready for electrophysiological recordings. These mechanically dissociated neurons differed from neurons dissociated using enzymes. Whereas the latter lost most, if not all, of the nerve terminals during the dissociation process, the former often preserved some functional nerve terminals ${ }^{[22,27,28,30]}$.

Electrophysiological recording The whole-cell patch clamp technique was used to record action potential and currents using pClamp 9.2 software (MDS Analytical Technologies, Sunnyvale, CA, USA) through a Digidata 1322A analog-to-digital converter (MDS Analytical Technologies) connected to an Axopatch 200B amplifier (MDS Analytical Technologies). The signals were filtered at $1 \mathrm{kHz}$ and sampled at $5 \mathrm{kHz}$. The junction potential between the pipette and the bath solution was nullified just before the giga-seal was formed.

The patch electrodes had a resistance of 3 to $5 \mathrm{M} \Omega$ when filled with pipette solution containing $140 \mathrm{mmol} / \mathrm{L} \mathrm{CsCl}$ or $\mathrm{KCl}, 2 \mathrm{mmol} / \mathrm{L} \mathrm{MgCl}_{2}, 4 \mathrm{mmol} / \mathrm{L}$ EGTA, $0.4 \mathrm{mmol} / \mathrm{L}$ $\mathrm{CaCl}_{2}, 10 \mathrm{mmol} / \mathrm{L}$ HEPES, $2 \mathrm{mmol} / \mathrm{L} \mathrm{Mg}$-ATP, and 0.1 $\mathrm{mmol} / \mathrm{L}$ GTP. The $\mathrm{pH}$ was adjusted to 7.2 with Tris-base, and the osmolarity was adjusted to 280 to $300 \mathrm{mOsm}$ with sucrose. Electrophysiological recordings were performed at room temperature $\left(22-24^{\circ} \mathrm{C}\right)$.

Chemicals and applications Most of the chemicals used in this study, including bicuculline methiodide, DL-2-amino5-phosphono-valeric acid (APV), 6,7-dinitroquinoxaline2,3-dione (DNQX), tetrodotoxin (TTX), dopamine, mecamylamine hydrochloride (MEC), dihydro- $\beta$-erythroidine hydrobromide (DH $\beta E$ ), $\alpha$-bungarotoxin ( $\alpha$-BTX), RJR-2403, and choline chloride were purchased from Sigma-Aldrich (St Louis, MO, USA). All solutions were freshly prepared on the day of use. Chemicals were applied to dissociated neurons with a Y-tube; this exchanged the external solution surrounding the neurons within $40 \mathrm{~ms}^{[28,30]}$.

Data analyses Spontaneous inhibitory postsynaptic currents (sIPSCs) were analyzed with Clampfit 9.2 software (MDS Analytical Technologies) as described previously ${ }^{[25,28]}$. In brief, the sIPSCs were screened automatically using a template with an amplitude threshold of $5 \mathrm{pA}$. These were visually accepted or rejected based upon rise and decay times. More than $95 \%$ of the sIPSCs that were visually accepted were screened using a suitable template. The frequency and 
amplitude of sIPSCs in different conditions were measured. Differences in amplitude and frequency were tested by Student's paired two-tailed $t$ test using the raw data. Numerical values are presented as mean \pm SEM. Values of $P<0.05$ were considered significant.

\section{Results}

Identification of SNc DA neurons The SNc was first identified in coronal slices with reference to the rat brain atlas ${ }^{[31]}$ using an inverted microscope and the DA neuron was then confirmed early in the recording session based on previously described criteria ${ }^{[10,32]}$ : (1) $1-3 \mathrm{~Hz}$ spontaneous firing (Figure 1A), (2) inhibition of spontaneous firing during exposure to $0.2 \mu \mathrm{mol} / \mathrm{L}$ quinpirole (Figure $1 \mathrm{~A}$ ), and (3) expression of a hyperpolarization-induced current ( $\mathrm{H}$-current; in voltage-clamp mode; Figure 1B).

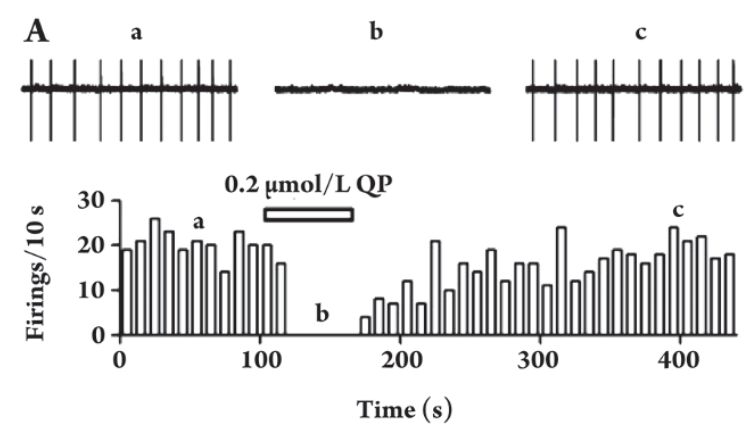

B

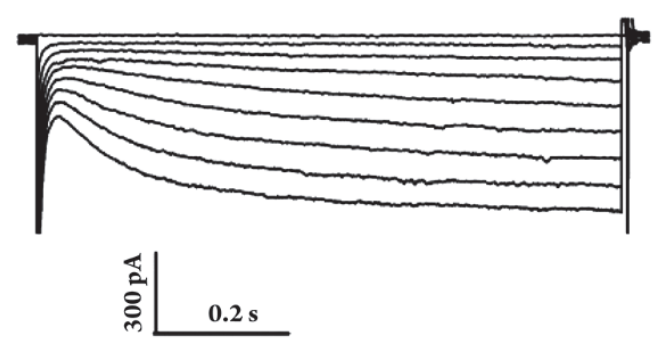

Figure 1. SNc DA neurons have distinct electrophysiological and pharmacological properties. A, spontaneous firing of a dissociated putative SNc DA neuron, which was reversibly depressed by $0.2 \mu \mathrm{mol} / \mathrm{L}$ quinpirole $(\mathrm{QP})$ (Upper panels: typical traces; Lower panel: time course). B, under voltage clamp mode, an $I_{\mathrm{h}}$ current was induced using a series of incremental $10 \mathrm{mV}$ hyperpolarizing steps from a holding potential of $-60 \mathrm{mV}$.

Properties of sIPSCs in mechanically dissociated SNc DA neuronal preparations We were able to record spontaneous postsynaptic currents (sPSCs) in $>80 \%$ of SNc DA neurons in mechanically dissociated neuronal preparations from $\mathrm{SNc}$ from midbrain slices. We isolated sIPSCs in voltage-clamped $\mathrm{SNc}$ DA neurons $\left(\mathrm{V}_{\mathrm{H}}=-55 \mathrm{mV}\right)$ by including 50 $\mu \mathrm{mol} / \mathrm{L} \mathrm{APV}$ and $20 \mu \mathrm{mol} / \mathrm{L} \mathrm{DNQX}$ in the perfusate. The reversible blockade by $10 \mu \mathrm{mol} / \mathrm{L}$ bicuculline indicates that these sIPSCs were mediated by $\mathrm{GABA}_{\mathrm{A}}$ receptors (Figure $2 \mathrm{~A}$ ). Consistent with our previous reports, the preparation, although simpler than brain slices in terms of synaptic connections, does contain the principal machinery for modulating neurotransmitter release. For instance, $1 \mu \mathrm{mol} / \mathrm{L}$ TTX (Figure $2 \mathrm{~B}$ ), $50 \mu \mathrm{mol} / \mathrm{L} \mathrm{CdCl}_{2}$ (Figure $2 \mathrm{C}$ ), or replacement of extracellular $\mathrm{Ca}^{2+}$ with $\mathrm{Mg}^{2+}$ (data not shown) reduced both the frequency and the amplitude of sIPSCs. The magnitude of these effects was as follows: frequency (illustrated in the upper panel of Figure 2D): TTX, by $62 \% \pm 10 \%$ (from $1.12 \pm 0.19$ to $0.46 \pm 0.17 \mathrm{~Hz}, n=6, P<0.01)$; $\mathrm{Cd}^{2+}$, by $79 \% \pm 3 \%$ (from $1.51 \pm 0.06$ to $0.32 \pm 0.03 \mathrm{~Hz}, n=5, P<0.01$ ); $0 \mathrm{Ca}^{2+}$, by $65 \% \pm 5 \%$ (from $1.33 \pm 0.24$ to $0.51 \pm 0.13 \mathrm{~Hz}, n=7, P<0.01$ ); and amplitude (illustrated in the lower panel of Figure 2D): TTX, by $33 \% \pm 8 \%$ (from $65.5 \pm 18.5$ to $44.7 \pm 12.4 \mathrm{pA}, n=6$, $P<0.01$ ); $\mathrm{Cd}^{2+}$, by $38 \% \pm 9 \%$ (from $54.5 \pm 7.6$ to $34.4 \pm 8.5$ pA, $n=5, P<0.01$ ); $0 \mathrm{Ca}^{2+}$, by $27 \% \pm 8 \%$ (from $31.7 \pm 5.6$ to $21.3 \pm 2.1 \mathrm{pA}, n=7, P<0.01)$. Moreover, incubation of the preparation in $30 \mu \mathrm{mol} / \mathrm{L}$ BAPTA-AM for $60-80 \mathrm{~min}$ eliminated almost all sIPSCs (data not shown). These results indicate that GABAergic synaptic transmission onto mechanically isolated SNc DA neurons is controlled by presynaptic voltage-gated sodium and calcium channels and also by extra- and intra-terminal $\mathrm{Ca}^{2+}$.

Nicotinic modulation of sIPSCs on SNc DA neurons Next, we examined the effect of nicotine on sIPSCs in SNc DA neurons. As illustrated in Figure 3C, nicotine significantly increased sIPSC frequency. On average, $1 \mu \mathrm{mol} / \mathrm{L}$ nicotine increased sIPSC frequency by $69 \% \pm 13 \%$ (from $1.2 \pm 0.2$ $\mathrm{Hz}$ to $1.9 \pm 0.2 \mathrm{~Hz}, n=5, P<0.01$, Figure $3 \mathrm{~F}$ ). Furthermore, 1 $\mu \mathrm{mol} / \mathrm{L}$ nicotine enhanced sIPSC amplitude by $42 \% \pm 16 \%$ (from $29 \pm 4 \mathrm{pA}$ to $39 \pm 2 \mathrm{pA}, n=5, P<0.05$, Figure $3 \mathrm{~F}$ ). In order to determine the subunit composition of the nAChRs that mediated nicotinic modulation of sIPSCs, we tested the modulation of sIPSCs by subtype-selective $\mathrm{nAChR}$ agonists, including choline for $\alpha 7 \mathrm{nAChRs}$ (Figure 3B), and RJR2403 for $\alpha 4 \beta 2^{*}$ nAChRs (Figure 3D). While choline (10 $\mathrm{mmol} / \mathrm{L}$ ) had no significant effect on sIPSCs (frequency: $98 \% \pm 9 \%$ of control; amplitude: $95 \% \pm 9 \%$ of control, $n=8$, $P>0.05$, Figure 3E), RJR-2403 (100 $\mu \mathrm{mol} / \mathrm{L})$ increased both the frequency (by $137 \% \pm 27 \%, n=7, P<0.001$ ) and the amplitude (by $47 \% \pm 20 \%, n=7, P<0.001$ ) (Figure $3 \mathrm{G}$ ) of sIPSCs. These results suggest that $\alpha 4 \beta 2^{*} \mathrm{nAChRs}$ are the principal subtype of $\mathrm{nAChR}$ that mediates nicotine enhancement of sIPSCs. 


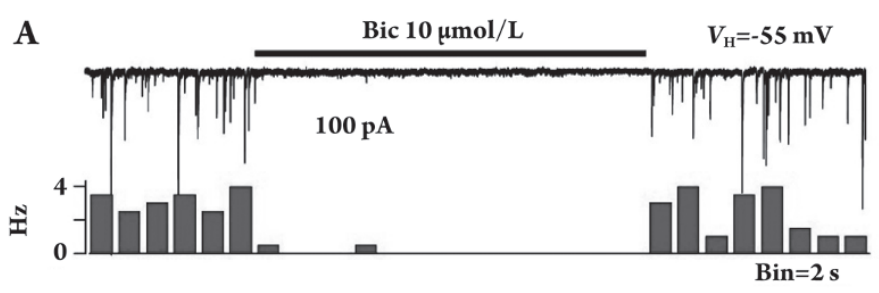

B
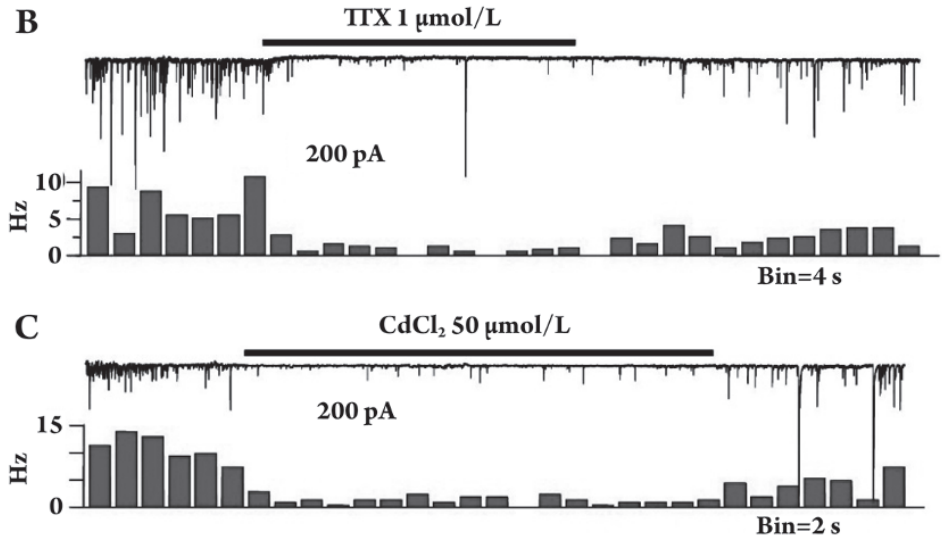

D
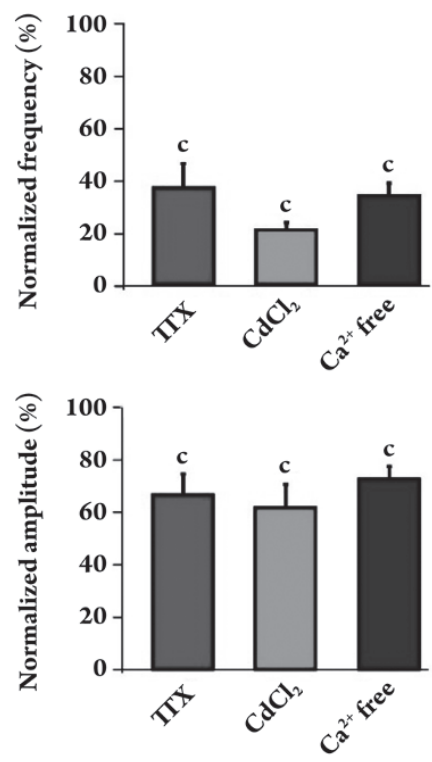

Figure 2. Spontaneous $\mathrm{GABA}_{\mathrm{A}}$ receptor-mediated IPSCs (sIPSCs) in DA neurons mechanically dissociated from the SNc. In the presence of 50 $\mu \mathrm{mol} / \mathrm{L} \mathrm{APV}$ and $20 \mu \mathrm{mol} / \mathrm{L} \mathrm{DNQX}$ and at a holding potential $\left(\mathrm{V}_{\mathrm{H}}\right)$ of $-55 \mathrm{mV}$, sIPSCs were completely but reversibly abolished by bicuculline (Bic, $10 \mu \mathrm{mol} / \mathrm{L})$ and were reversibly and significantly inhibited by TTX $(1 \mu \mathrm{mol} / \mathrm{L})$ and by $\mathrm{CdCl}_{2}(50 \mu \mathrm{mol} / \mathrm{L})$. Summary data (means \pm SEM $)$ shows the effects of TTX, $\mathrm{CdCl}_{2}$ and calcium free $\left(\mathrm{Ca}^{2+}\right.$ free) on the frequency (upper panel) and amplitude of sIPSCs (lower panel). ${ }^{\mathrm{c}} \mathrm{P}<0.01 \mathrm{compared}$ to control.

A

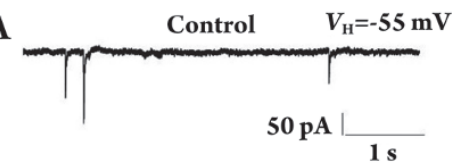

B

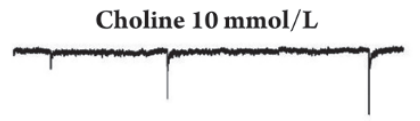

C

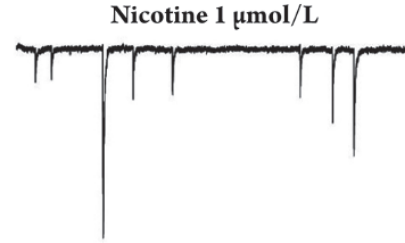

D

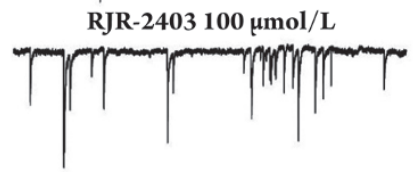

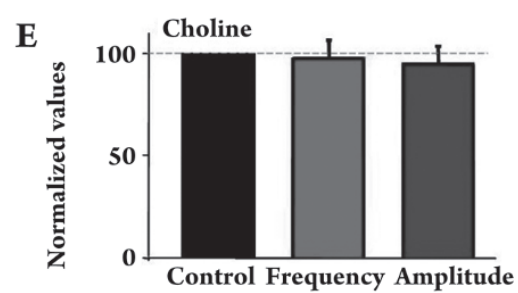
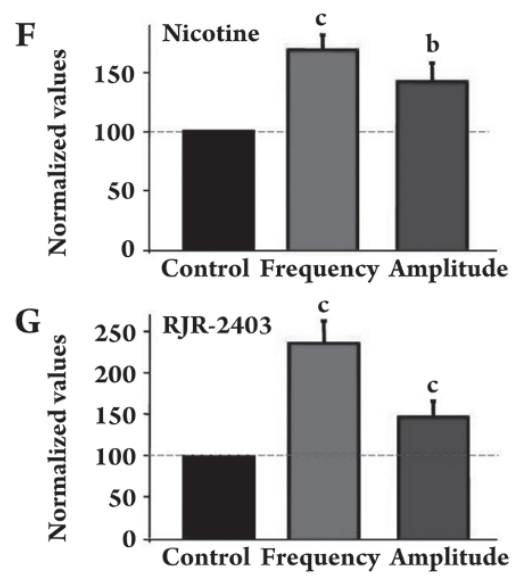

Figure 3. Effects of nicotinic agonists on sIPSCs in SNc DA neurons. Typical traces of sIPSCs recorded under the control condition (A) and in the presence of $10 \mathrm{mmol} / \mathrm{L}$ choline (B), $1 \mu \mathrm{mol} / \mathrm{L}$ nicotine (C), and $100 \mu \mathrm{mol} / \mathrm{L}$ RJR-2403 (D). All traces were from the same $\mathrm{SNc}$ DA neuron $\left(V_{\mathrm{H}}=-55 \mathrm{mV}\right)$. E-G: Summary of the effects of choline (E), nicotine (F), and RJR-2403 (G) on both frequency and amplitude of sIPSCs. ${ }^{b} P<0.05,{ }^{c} P<0.01$ compared to control.
SNc DA neurons receive cholinergic innervation from lateral dorsal tegmentum and peduncular pontine tegmentum ${ }^{[2]}$. Acetylcholinesterase (AChE) is densely expressed in $\mathrm{SNc}^{[33]}$. In order to determine whether our preparations exhibit tonic $\mathrm{ACh}$ release and $\mathrm{AChE}$ presence, we tested the effect of eserine (an AChE inhibitor) on sIP- 
SCs in the presence of $0.5 \mu \mathrm{mol} / \mathrm{L}$ atropine, an antagonist of muscarinic AChRs. Under these experimental conditions, eserine $(3 \mu \mathrm{mol} / \mathrm{L})$ significantly increased sIPSC frequency, by $70 \% \pm 17 \%$ (from $0.83 \pm 0.21 \mathrm{~Hz}$ to $1.28 \pm 0.25 \mathrm{~Hz}, n=5$, $P=0.004)$ but did not significantly alter sIPSC amplitude (by $-11 \% \pm 7 \%$, from $58 \pm 19$ pA to $51 \pm 12$ pA, $n=5, P>0.05$ ) (Figure 4A, 4B). This result supports the idea that the mechanically dissociated SNc DA neurons contain attached cholinergic nerve terminals. Furthermore, these cholinergic terminals appear to tonically release $\mathrm{ACh}$, which modulates GABA release onto $\mathrm{SNc}$ neurons.

Subtypes of $\mathbf{n A C h R s}$ in GABAergic terminals synapsing onto SNc DA neurons In order to address the question of whether tonically released $\mathrm{ACh}$ in our preparations can activate presynaptic nAChRs, we determined the effects of $\mathrm{nAChR}$ antagonists on sIPSCs. Perfusion of $\alpha$-bungarotoxin ( $\alpha$-BTX, $300 \mathrm{nmol} / \mathrm{L}$, Figure 5B), a specific $\alpha 7 \mathrm{nAChR}$ antagonist, did not significantly alter sIPSC frequency (95\% $\pm 6 \%$ of control, from $0.77 \pm 0.17 \mathrm{~Hz}$ to $0.67 \pm 0.14 \mathrm{~Hz}$, $n=7, P=0.21$, Figure 5F, 5G), whereas a 5-min incubation with mecamylamine hydrochloride (MEC, $10 \mu \mathrm{mol} / \mathrm{L}$, Figure 5D), a broad spectrum $\mathrm{nAChR}$ antagonist, significantly depressed sIPSC frequency (by $42 \% \pm 5 \%$, from $1.53 \pm 0.40$ $\mathrm{Hz}$ to $0.90 \pm 0.27 \mathrm{~Hz}, n=6, P=0.02$, Figure $5 F, 5 G)$. Similarly, the application of dihydro- $\beta$-erythroidine hydrobromide $\left(\mathrm{DH} \beta \mathrm{E}, 100 \mathrm{nmol} / \mathrm{L}\right.$, Figure 5C), an antagonist for $\alpha 4 \beta 2^{*}$ nAChRs, decreased sIPSC frequency (by $39 \% \pm 4 \%$, from $1.79 \pm 0.40 \mathrm{~Hz}$ to $1.06 \pm 0.22 \mathrm{~Hz}, n=6, P=0.006$, Figure $5 \mathrm{~F}$,
$5 G)$. These data indicate that the principal subtypes of $n A C h R s$ that mediate the endogenous ACh modulation of sIPSCs contain $\alpha 4 \beta 2$ subunits.

\section{Discussion}

Mechanically dissociated neuronal preparations from many brain regions have been used to study the modulation of spontaneous postsynaptic events in hippocampus, VTA, SNc, periaqueductal gray, and other areas of the brain $^{[22-28,30]}$. Although these preparation give the appearance of single neurons, they appear to contain attached synaptic boutons, where this interpretation is supported by the existence of vesicles and pre- and post-synaptic structures that are revealed, respectively, by FM1-43 staining and electron microscopy ${ }^{[22,27]}$. Interestingly, this preparation retains the machinery that controls neurotransmitter release, including voltage-gated sodium and calcium channels, many types of presynaptic receptors, and the potential to undergo calcium elevation ${ }^{[22-28,30]}$. Consistent with these findings, we observed that TTX, $\mathrm{Cd}^{2+}$, and elimination of extracellular calcium reduce sIPSC frequency in mechanically dissociated SNc DA neurons, and that chelation of calcium in preand post-synaptic structures using BAPTA-AM eliminates the sIPSCs. It is noteworthy that the amplitude of sIPSCs recorded in mechanically dissociated DA neurons usually reaches tens to $200 \mathrm{pA}$, a range of values that is many times larger than single vesicle $G A B A$ release-induced $G_{A B A}$

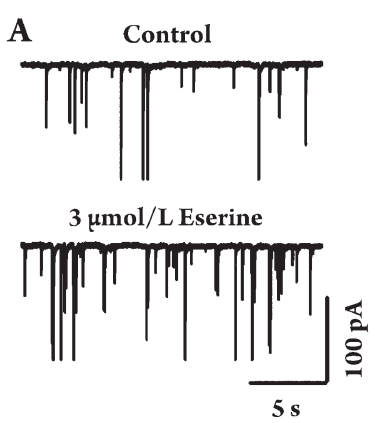

C1

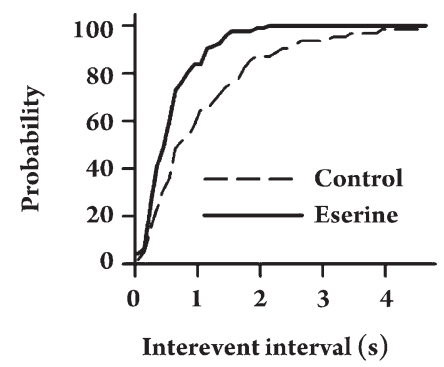

B

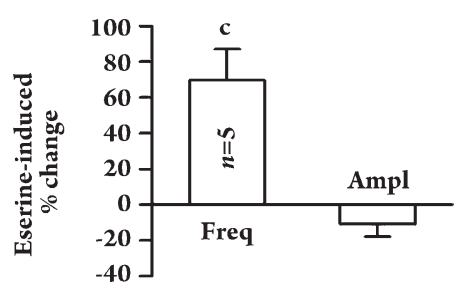

C2

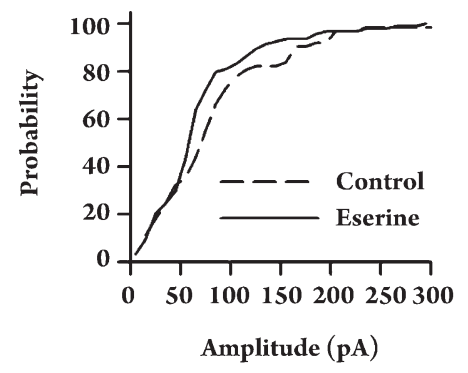

Figure 4. Eserine enhances sIPSCs in SNc DA neurons. A-B, Eserine increases the frequency (Freq), but not amplitude (Ampl) of sIPSCs (A, typical traces; B, summary). C1 and $\mathrm{C} 2$, Eserine causes a leftward shift of the cumulative probability of interevent intervals of two consecutive sIPSCs (C1, K-S test, $P<0.001)$, but not that of sIPSC amplitude (C2, $\mathrm{K}-\mathrm{S}$ test, $P=0.13$ ). 
A

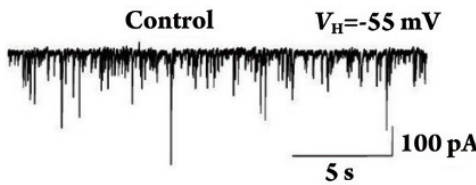

B

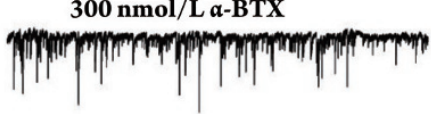

C

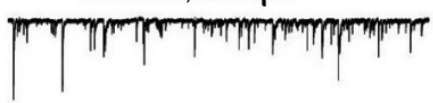

D

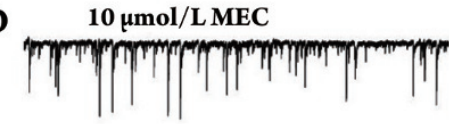

$\mathbf{E}$

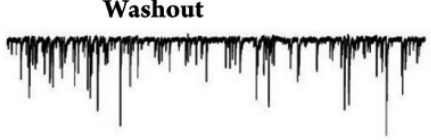

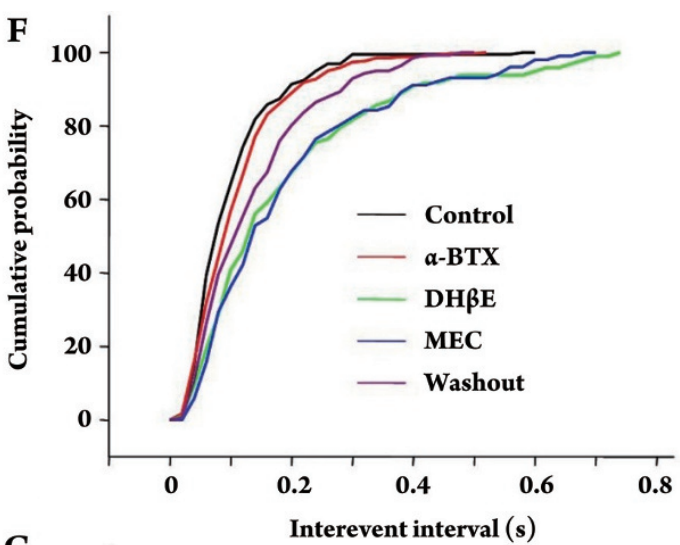

G

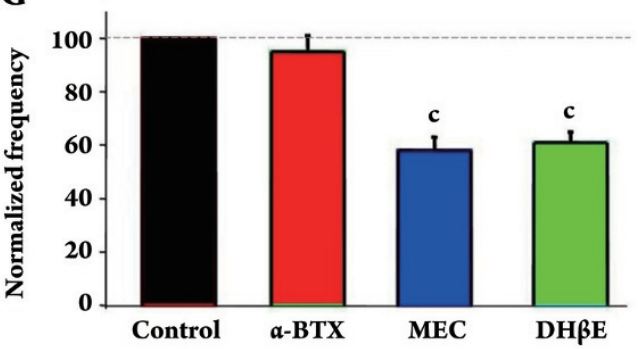

Figure 5. Effects of nicotinic antagonists on sIPSCs in SNc DA neurons. Representative traces of sIPSCs recorded under control conditions (A), in the presence of $300 \mathrm{nmol} / \mathrm{L} \alpha-\mathrm{BTX}$ (B), $100 \mathrm{nmol} / \mathrm{L} \mathrm{DH \beta E} \mathrm{(C),} 10 \mu \mathrm{mol} / \mathrm{L}$ MEC (D), and after 10 min washout (E) with the standard external solution. All traces were from the same DA neuron $\left(V_{\mathrm{H}}=-55 \mathrm{mV}\right)$. F: Cumulative probability plots show that DH $\beta \mathrm{E}$ and MEC significantly increased incidence of long sIPSC interevent intervals (K-S test, $P<0.001)$, but that $\alpha$-BTX did not significantly alter the distribution of sIPSC interevent intervals (K-S test, $P>0.05$ ). G: Summary of the effects of $\alpha$-BTX, DH $\beta E$, MEC on the frequency of sIPSCs. ${ }^{c} P<0.01$ compared to control.

receptor current, which has a magnitude of several pA. This suggests that synchronized release of GABA is common in GABAergic terminals which make synapses onto $\mathrm{SNc}$ DA neurons. This interpretation is supported by the fact that TTX, $\mathrm{Cd}^{2+}$, and elimination of extracellular calcium all reduced sIPSC amplitude.

We showed that nicotine enhanced both the frequency and amplitude of sIPSCs in SNc DA neurons. The enhancement of sIPSCs by nicotine in our preparation suggests that the GABAergic terminals innervating the SNc DA neurons possess presynaptic nAChRs and that activation of these receptors can increase both the frequency and synchrony of GABA release. Further experiments examining nicotine's effects on the desynchronized GABA release are warranted in order to clarify this possibility. Surprisingly, the elevation of endogenous ACh by $3 \mu \mathrm{mol} / \mathrm{L}$ eserine enhanced sIPSC frequency as much as did $1 \mu \mathrm{mol} / \mathrm{L}$ nicotine (Figure $3 \mathrm{~F}$ and Figure 4B), while it did not change sIPSC amplitude. This suggests that nicotine, rather than $\mathrm{ACh}$, which predominantly activates $\mathrm{nAChRs}$ in the presence of $0.5 \mu \mathrm{mol} / \mathrm{L}$ atropine, increases the probability of synchronization in GABA release. It is worth noting that, unlike nicotine, $\mathrm{ACh}$ is not permeable to the membrane $e^{[34]}$. We postulate that intraterminal nicotine affects the synchrony of GABA release, leading to larger amplitude of sIPSCs.

Our pharmacological examinations in mechanically dissociated SNc DA neurons showed that DH $\beta E$ and MEC, but not $\alpha$-bungarotoxin, reduce the frequency of sIPSCs in these neurons and that RJR-2403, but not choline, increases the frequency of sIPSCs. This suggests, first, that there is tonic $\mathrm{ACh}$ released from cholinergic terminals attached to the isolated SNc DA neurons; second, that the ACh concentration achieved by this release is sufficient to activate the presynaptic nAChRs; and third, that $\alpha 4 \beta 2^{*} \mathrm{nAChRs}$ may be the principal type of $\mathrm{nAChR}$ located on the GABAergic terminals. The GABAergic innervation to $\mathrm{SNc} D A$ neurons originates from $\mathrm{SNr}$, dorsal striatum, and globus pallidus; however, functional $\alpha 4 \beta 2^{*} \mathrm{nAChRs}$ were detected only in SNr GABAergic neurons ${ }^{[4,10]}$, while high-affinity nicotine binding and $a 4$ subunit expression are detectable only in the neuronal processes of the dorsal striatum ${ }^{[10,21]}$. Therefore, in the substantia nigra, nicotinic modulation of GABAergic tone to SNc DA neurons may be primarily mediated by $\alpha 4 \beta 2^{*} \mathrm{nAChRs}$ in SNr GABAergic neurons. 


\section{Author contribution}

Cheng XIAO, Ke-chun YANG, and Chun-yi ZHOU performed patch-clamp experiments and data analysis. Cheng $\mathrm{XIAO}$ and Ke-chun YANG wrote the manuscript. Cheng XIAO designed experiments. Guo-zhang JIN revised the manuscript. Jie WU and Jiang-hong YE designed experiments, analyzed data and revised the manuscript.

\section{References}

1 Grant BF, Hasin DS, Chou SP, Stinson FS, Dawson DA. Nicotine dependence and psychiatric disorders in the United States: results from the national epidemiologic survey on alcohol and related conditions. Arch Gen Psychiatry 2004; 61: 1107-15.

2 Dani JA, Bertrand D. Nicotinic acetylcholine receptors and nicotinic cholinergic mechanisms of the central nervous system. Annu Rev Pharmacol Toxicol 2007; 47: 699-729.

3 Mansvelder HD, Keath JR, McGehee DS. Synaptic mechanisms underlie nicotine-induced excitability of brain reward areas. Neuron 2002; 33: 905-19.

4 Wooltorton JR, Pidoplichko VI, Broide RS, Dani JA. Differential desensitization and distribution of nicotinic acetylcholine receptor subtypes in midbrain dopamine areas. J Neurosci 2003; 23: 317685.

5 Di Chiara G, Imperato A. Drugs abused by humans preferentially increase synaptic dopamine concentrations in the mesolimbic system of freely moving rats. Proc Natl Acad Sci USA 1988; 85: 5274-8.

6 Imperato A, Mulas A, Di Chiara G. Nicotine preferentially stimulates dopamine release in the limbic system of freely moving rats. Eur J Pharmacol 1986; 132: 337-8.

7 Azam L, Winzer-Serhan UH, Chen Y, Leslie FM. Expression of neuronal nicotinic acetylcholine receptor subunit mRNAs within midbrain dopamine neurons. J Comp Neurol 2002; 444: 260-74.

8 Champtiaux N, Gotti C, Cordero-Erausquin M, David DJ, Przybylski C, Lena C, et al. Subunit composition of functional nicotinic receptors in dopaminergic neurons investigated with knock-out mice. J Neurosci 2003; 23: 7820-9.

9 Klink R, de Kerchove d'Exaerde A, Zoli M, Changeux JP. Molecular and physiological diversity of nicotinic acetylcholine receptors in the midbrain dopaminergic nuclei. J Neurosci 2001; 21: 1452-63.

10 Nashmi R, Xiao C, Deshpande P, McKinney S, Grady SR, Whiteaker $\mathrm{P}$, et al. Chronic nicotine cell specifically upregulates functional alpha $4^{*}$ nicotinic receptors: basis for both tolerance in midbrain and enhanced long-term potentiation in perforant path. J Neurosci 2007; 27: 8202-18.

11 Johnson SW, North RA. Two types of neurone in the rat ventral tegmental area and their synaptic inputs. J Physiol 1992; 450: 455-68.

12 Tepper JM, Martin LP, Anderson DR. GABAA receptor-mediated inhibition of rat substantia nigra dopaminergic neurons by pars reticulata projection neurons. J Neurosci 1995; 15: 3092-103.

13 Xiao C, Zhang J, Krnjevic K, Ye JH. Effects of ethanol on midbrain neurons: role of opioid receptors. Alcohol Clin Exp Res 2007; 31 :
1106-13.

14 McGehee DS, Heath MJ, Gelber S, Devay P, Role LW. Nicotine enhancement of fast excitatory synaptic transmission in CNS by presynaptic receptors. Science 1995; 269: 1692-6.

15 Wonnacott S. Presynaptic nicotinic ACh receptors. Trends Neurosci 1997; 20: 92-8.

16 MacDermott AB, Role LW, Siegelbaum SA. Presynaptic ionotropic receptors and the control of transmitter release. Annu Rev Neurosci 1999; 22: 443-85.

17 Bolam JP, Smith Y. The GABA and substance P input to dopaminergic neurones in the substantia nigra of the rat. Brain Res 1990; 529: 57-78.

18 Smith AD, Bolam JP. The neural network of the basal ganglia as revealed by the study of synaptic connections of identified neurones. Trends Neurosci 1990; 13: 259-65.

19 Smith Y, Bolam JP. The output neurones and the dopaminergic neurones of the substantia nigra receive a GABA-containing input from the globus pallidus in the rat. J Comp Neurol 1990; 296: 47-64.

20 Quik M, Polonskaya Y, McIntosh JM, Kulak JM. Differential nicotinic receptor expression in monkey basal ganglia: effects of nigrostriatal damage. Neuroscience 2002; 112: 619-30.

21 Rogers SW, Gahring LC, Collins AC, Marks M. Age-related changes in neuronal nicotinic acetylcholine receptor subunit alpha4 expression are modified by long-term nicotine administration. J Neurosci 1998; 18: 4825-32.

22 Akaike N, Moorhouse AJ. Techniques: applications of the nervebouton preparation in neuropharmacology. Trends Pharmacol Sci 2003; 24: 44-7.

23 Deng C, Li KY, Zhou C, Ye JH. Ethanol enhances glutamate transmission by retrograde dopamine signaling in a postsynaptic neuron/synaptic bouton preparation from the ventral tegmental area. Neuropsychopharmacology 2009; 34: 1233-44.

24 Xiao C, Zhou C, Atlas G, Delphin E, Ye JH. Labetalol facilitates GABAergic transmission to rat periaqueductal gray neurons via antagonizing beta1-adrenergic receptors-a possible mechanism underlying labetalol-induced analgesia. Brain Res 2008; 1198: $34-43$.

25 Xiao C, Zhou C, Li K, Davies DL, Ye JH. Purinergic type 2 receptors at $\mathrm{GABAergic}$ synapses on ventral tegmental area dopamine neurons are targets for ethanol action. J Pharmacol Exp Ther 2008; 327: 196-205.

26 Xiao C, Zhou C, Li K, Ye JH. Presynaptic GABAA receptors facilitate GABAergic transmission to dopaminergic neurons in the ventral tegmental area of young rats. J Physiol 2007; 580: 731-43.

27 Ye JH, Wang F, Krnjevic K, Wang W, Xiong ZG, Zhang J. Presynaptic glycine receptors on GABAergic terminals facilitate discharge of dopaminergic neurons in ventral tegmental area. J Neurosci 2004; 24: 8961-74.

28 Zhou C, Xiao C, McArdle JJ, Ye JH. Mefloquine enhances nigral gamma-aminobutyric acid release via inhibition of cholinesterase. J Pharmacol Exp Ther 2006; 317: 1155-60.

29 Ye JH, Zhang J, Xiao C, Kong JQ. Patch-clamp studies in the CNS illustrate a simple new method for obtaining viable neurons in rat brain slices: glycerol replacement of $\mathrm{NaCl}$ protects $\mathrm{CNS}$ neurons. J Neurosci Methods 2006; 158: 251-9.

30 Zhou C, Xiao C, Commissiong JW, Krnjevic K, Ye JH. Mesencephalic astrocyte-derived neurotrophic factor enhances nigral 
gamma-aminobutyric acid release. Neuroreport 2006; 17: 293-7.

31 Paxinos G, Watson C. The rat brain in stereotaxic coordinates. Ed 2nd. San Diego (CA): Academic Press; 1998.

32 Lacey MG, Mercuri NB, North RA. Two cell types in rat substantia nigra zona compacta distinguished by membrane properties and the actions of dopamine and opioids. J Neurosci 1989; 9: 123341.

33 Emmett SR, Greenfield SA. Correlation between dopaminergic neurons, acetylcholinesterase and nicotinic acetylcholine receptors containing the alpha3- or alpha5-subunit in the rat substantia nigra. J Chem Neuroanat 2005; 30: 34-44.

34 Lester HA, Xiao C, Srinivasan R, Son CD, Miwa J, Pantoja R, et al. Nicotine is a selective pharmacological chaperone of acetylcholine receptor number and stoichiometry. Implications for drug discovery. AAPS J 2009; 11: 167-77. 